\title{
Havza Büyüklüğüne Göre En Uygun Taşkın Debisi Hesap Yönteminin Bulunması - Doğu Akdeniz Havzası Örneği
}

\author{
Mehmet DİKİCi' ${ }^{1}$, Murat AKSEL ${ }^{1 *}$ \\ ${ }^{1}$ Alanya Alaaddin Keykubat Üniversite, Rafet Kayış Mühendislik Fakültesi,Inşaat Mühendisliği Bölümü, \\ Şehir, Ülke. \\ *murat.aksel@alanya.edu.tr
}

\begin{abstract}
Özet
Taşkın, son yıllarda iklim değişikliği ve şehirleşmenin de etkisiyle sayısız zararlara yol açan bir doğal afettir. Taşkının zamanını, büyüklüğünü ve şiddetini bilmek; taşkının olumsuz etkilerini azaltmak için son derece önemlidir. Taşkının hidrolik modellemesinin yapılarak etki alanı tahmin edilebilir. Bunun için de maksimum taşkın debisini bilmek gerekir. İstatistik, sentetik ve hidrolojik model yöntemleri ile hesaplanan taşkın debisinin oluşturduğu taşkın hidrografı, hidrolik modele altlık olur ve taşkın risk haritaları belirlenebilir. Bu çalışmada Mockus, Snyder, Rasyonel ve DSi sentetik yöntemleri ile taşkın frekans analizi ve ayrıca MIKE hidrolojik model programı yardımıyla taşkın pik debileri, $21.682,8 \mathrm{~km}^{2}$ alana sahip Doğu Akdeniz Havzası için hesaplanmıştır. Sonuç olarak geniş bir havzada çok sayıda gözlem istasyonu yardımıyla havza büyüklüğüne göre en uygun taşkın debisi tahmin yöntemleri belirlenmiştir.
\end{abstract}

Anahtar Kelimeler: Hidrolojik model, frekans analizi, sentetik yöntem, taşkın debisi

\section{Determining the Best Method of Flood Flow Rate Estimation Based on Basin Size: A Case Study of the Eastern Mediterranean Basin}

\section{Abstract}

Flood is a natural disaster that has caused countless damages in recent years due to the climate change and urbanization. Estimating the time, magnitude and severity of the flood is crucial to reducing its negative impacts. The target areas of flood can be estimated by the hydraulic model of the flood. It is essential to know the maximum flood flow rate for hydraulic modeling. The flood hydrograph generated by the flood flow rate which is estimated by statistics, synthetic and hydrological model methods provides a basis for the hydraulic model and the risk maps of the flood can be defined. In this study flood frequency analysis with Mockus, Snyder, Rasyonel and DSI synthetic methods and flood peaks with the help of MIKE hydrological modeling software were calculated for the eastern Mediterranean basin area of 21,682.8 km². As a result, the most appropriate methods of flood forecasting based on basin size were determined with the help of several observation stations in a wide basin.

Keywords: Hydrological model, frequency analysis, flood peak flow, synthetic method 


\section{GíRiş}

İklim değişikliği ve şehirleşmenin beraberinde getirdiği olumsuzluklardan olan kuraklık ve taşkın; su yönetiminin iki ana konusudur. Kuraklık yavaş seyreden ancak uzun vadede kalıcı hasara sebep olan bir afettir. Taşkın ise aniden meydana gelen, mevsime bağlı olmaksızın etkisi şiddetli olabilen, tarım ve yerleşim alanlarına zarar veren bir afet çeşididir. Taşkına karşı önlem alınabilmesi için havzada oluşabilecek maksimum taşkın debisinin bilinmesi hayati derecede önemlidir.

Sentetik, istatistiksel ve hidrolojik model yöntemi ile maksimum taşkın debileri bulunabilir. Klasik yöntemler olarak da adlandırılan, sentetik yöntemler ile havzanın fiziksel özelliklerine bağlı olarak maksimum taşkın debisini bulmak için çeşitli formüller geliştirilmiş ve uygulanmıştır [1-8]. Sönmez ve ark. 2012 yılında [9] Snyder, Kirpich, Mockus ve S.C.S yöntemlerini İstanbul örneği için seçilen 8 adet dereye uygulamıştır. Türkiye'de benzer çalışmalarda sentetik yöntemler kullanılmıştır [10-12]. İstatistiksel yöntemlerle yapılan taşkın frekans analizleri de oldukça yaygındır [13-17]. Türkiye'de [18,19] ve Dünya'da taşkın frekans analizine örnek bir çok çalışma yapılmıştır [20-22]. Hidrolojik model oluşturulması da yine maksimum taşkın debisi hesabında kullanılan ve bilgisayar programlarılyla desteklenen bir yöntemdir. Çok sayıda modelleme programı arasında bu çalışmada kullanılan MIKE programı da en yaygın olarak çeşitli çalışmalarda kullanılan bilgisayar programlarındandır [23-25].

$\mathrm{Bu}$ çalışma kapsamında riskli olduğuna kanaat getirilmiş ve aynı zamanda Horton Strahler Metodu ile belirlenen ana 3 kol ile nehir kollarında yapılacak hidrolik modelleme çalışmalarına altlık oluşturacak hidrolojik çalışmalar yapılmıştır. Yeterli havza büyüklüğüne sahip olan dere kollarının hidrolojik analizleri; sentetik yöntemler, hidrolojik model, veri uygunluğu olan noktalarda noktasal ve bölgesel taşkın frekansı analizi yapılmıştır. Bu hesaplamalar kendi aralarında ve DSİ ( Devlet Su İşleri) işletmelerinin planlama taşkın yineleme debileri ile karşılaştırılmıştır. Taşkın hidrograflarının elde edilmesi temel amaçtır. Havzanın tarihsel arşivi de göz önünde bulundurularak, hidroloji çalışmalarında değerlendirilmek üzere 156 taşkın riski olan yerleşim yeri belirlenmiştir. Risk oluşturan yerleşim yerlerinde dereler üzerinde 160 adet hidrograf noktası belirlenmiş ve hidroloji çalışmaları bu noktalar için gerçekleştirilmiştir. Çalışmalarda Q2, Q5, Q10, Q25, Q50, Q100, Q500 ve Q1000 taşkın tekerrür debileri hesaplanmıştır. Yukarıda sözü edilen tekerrür debilerinin hesaplamalarında istatistik yöntemler, hidrolojik model ve sentetik yöntemler (Rasyonel, Mockus, DSİ sentetik, Snyder) uygulanmıştır. Havza büyüklüklerine göre uygulanan yöntemler birbirleri ile karşılaştırılmış ve güvenli yanda kalınarak Q100 debisine göre yüksek sonuç veren metot ileriki çalışmalarda kullanılmak üzere seçilmiştir. Çalışmanın sonunda elde edilen farklı periyotlar için bulunan taşkın debilerinin hangi havza büyüklügü için hangi yöntemle belirlenmesinin daha doğru sonuç verdiği de analiz edilmiştir.

\section{MATERYAL VE YÖNTEM}

\section{1. Çalışma Alanı}

Doğu Akdeniz Havzası; Türkiye'nin güneyinde bulunmaktadır. Havza'nın kuzeyinde Konya Kapalı havzası ve küçük bir bölümde Seyhan Havzası, doğusunda Seyhan Havzası, güneyinde Akdeniz, batısında Antalya Havzası bulunmaktadır. Havza'nın toplam alanı 21682,8 km² olmakla birlikte Konya, Antalya, Karaman ve Mersin İllerinin tamamını ve/veya bir kısmını kapsamaktadır (Şekil 1).

Thiessen Çokgenleri Yöntemine göre Doğu Akdeniz Havzası'nın gölle kaplı alanlarının ve kara yüzeylerinin üzerine düşen yıllık uzun yıllara ait ortalama toplam yağış miktarı 708 mm'dir. Gölle kapalı alanların üzerine düşen uzun yıllara ait yıllık ortalama toplam yağış miktarı ise $605 \mathrm{~mm}$ 'dir. Bütün istasyonlar dikkate alınarak hesaplanan yıllık ortalama sıcaklık $15{ }^{\circ} \mathrm{C}$ olarak elde edilmiştir. En düşük sıcaklık Şubat ayında Arslanköy'de $-23,5^{\circ} \mathrm{C}$ olarak ölçülmüştür. En yüksek sıcaklık ise Ağustos ayında Mut'ta $46,7^{\circ} \mathrm{C}$ olarak ölçülmüştür. Doğu Akdeniz Havzası'nın istasyonlardaki ölçümlere göre uzun yıllara 
ait yıllık ortalama toplam buharlaşma miktarı 1095 mm (Hadim) ile 1779 mm (Berdan Barajı) arasında değişmektedir.

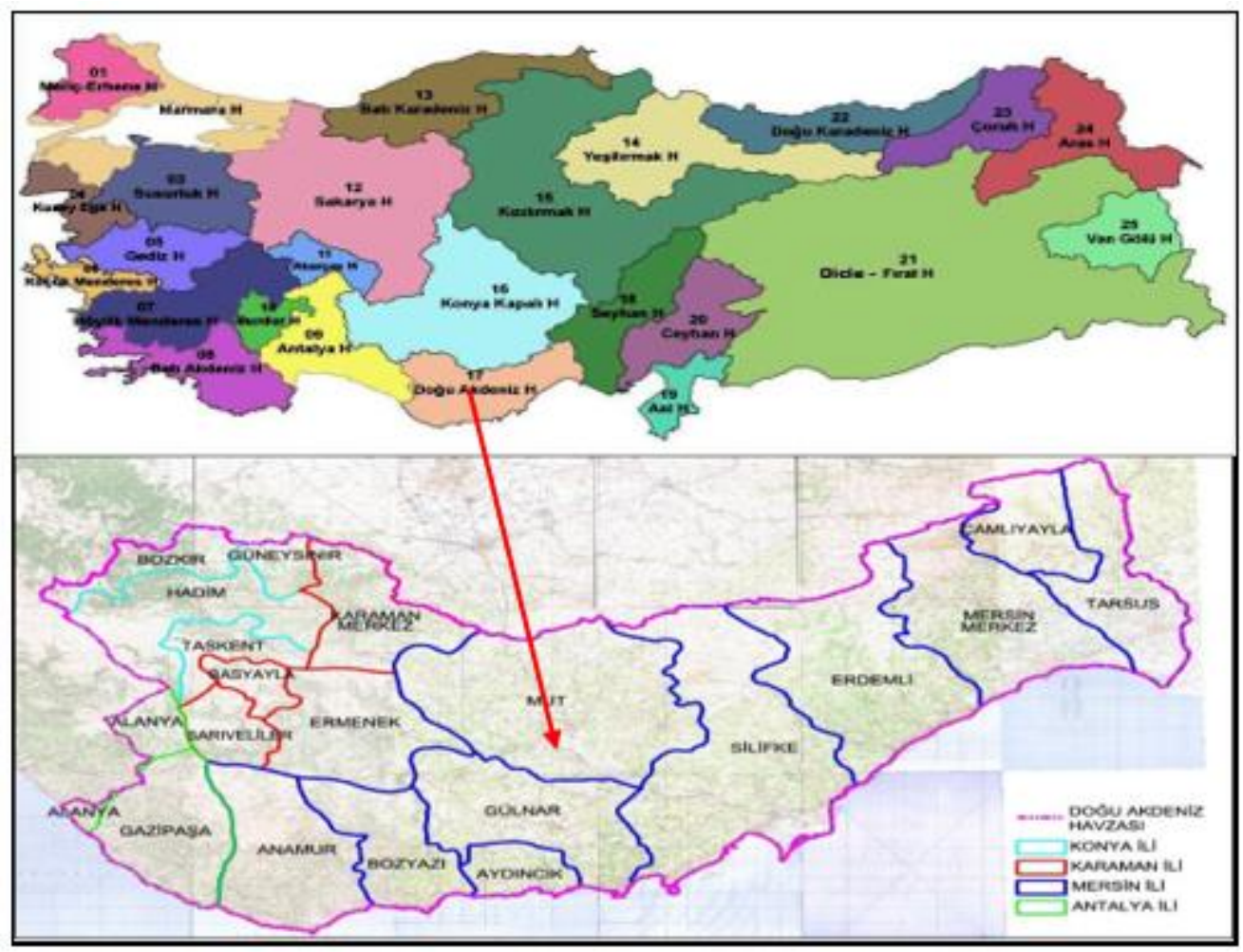

Şekil 1. Doğu Akdeniz Havzası'nın yer bulduru haritası

\subsection{Hidroloji Çalışmalarında Kullanılan Veriler}

Hidroloji çalışmalarında temel olarak Sayısal Yükseklik Modeli, Meteoroloji Gözlem İstasyonu (MGi) verileri, Akım Gözlem İstasyonu (AGI) verileri, havzada bulunan rezervuarların özellikleri, havzadaki toprağın fiziksel parametreleri ve arazi örtüsü verileri gereklidir. Hidroloji çalışmaları yapılırken, sentetik yöntemler, hidrolojik model, veri uygunluğu olan noktalarda noktasal ve bölgesel taşkın frekansı analizi yapılarak gerçekleştirilmiş ve hidrograflar elde edilmiştir. Doğu Akdeniz Havzası'nda ve dolayında verisine erişilebilen ve uygun olan 28 adet MGİ ve 32 adet AGİ hidroloji çalışmaları kapsamında değerlendirilmiş ve verileri kullanılmıştır. Kullanılan veriler ile toplam 156 riskli yerleşim yeri için 160 adet noktada sentetik yöntemler ve modelleme çalışmaları kullanılarak hidrograflar üretilmiştir.

1/25000 ölçekli E00 formatındaki eşyükselti eğrileri ve tepe noktaları uygun formata dönüştürülerek analize hazır hale getirilmiştir. Sonrasında ise bu veriler kullanılarak havza genelinde vektörel sayısal arazi modeli olan düzensiz üçgenler ağı (TIN) oluşturulmuştur.

Doğu Akdeniz Havzası ve civarında bulunan 42 adet meteoroloji gözlem istasyonu Meteoroloji Genel Müdürlüğü ve Devlet Su İşleri'nden temin edilip, incelenmiştir. Şekil 2'de yerleşimleri sunulan 28 adet MGİ'nin aylık toplam yağış değerleri klasik hidroloji çalışmalarında kullanılmıştır. 10 adet MGİ'nin günlük toplam yağış ve 8 adet günlük ortalama sıcaklık; 5 adet meteoroloji gözlem istasyonunun buharlaşma verileri hidrolojik modelleme kapsamında değerlendirilmiştir. Bununla birlikte modellenecek havzayı temsil edebilecek buharlaşma verisinin bulunmadığı ortamlarda ise buharlaşma sıcaklık istasyonu verisi kullanılarak literatürde en yaygın iki yöntemden biri olan Thornthwaite yöntemi ile hesaplanmıştır. 


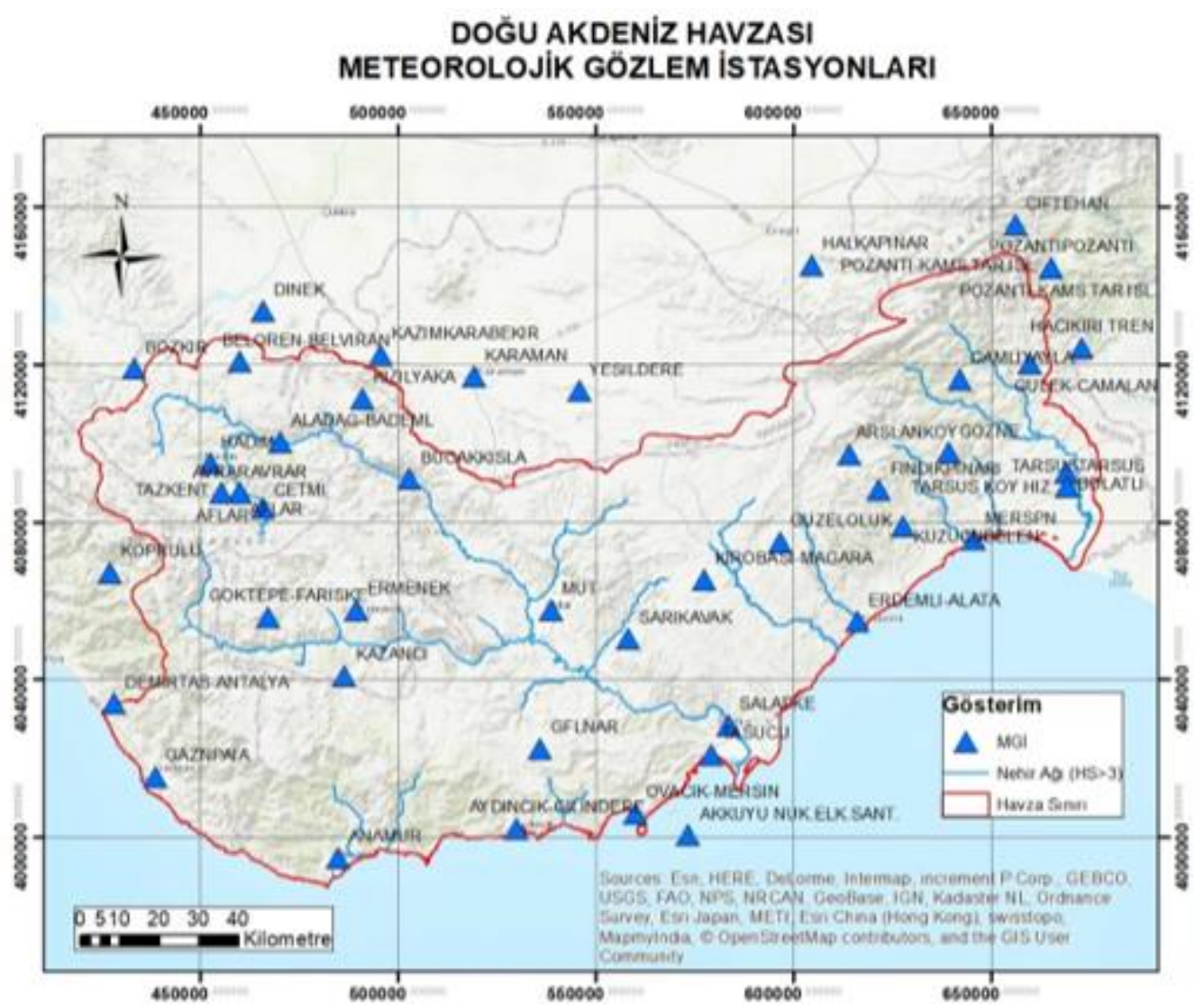

Şekil 2. Doğu Akdeniz Havzası içinde bulunan MGİ noktalarının konumları

Doğu Akdeniz Havzası'nda bulunan ve debi değerleri mevcut olan toplam 73 AGI'den 12 adeti klasik hidroloji hesaplarında değerlendirme kapsamına alınmıştır. Ancak bu AGİ'lerden Şekil 3'de yerleşimi sunulan 7 tanesinin verileri doğrudan hidrolojik modelde kalibrasyon girdisi olarak, 2 tanesi de validasyon olarak kullanılmıştır. AGİ verileri, ölçülmüş akım değerleri olarak hidrolojik modelin verdiği akış çıktılarıyla karşılaştırılarak kalibrasyon verisi olarak kullanılmıştır. 


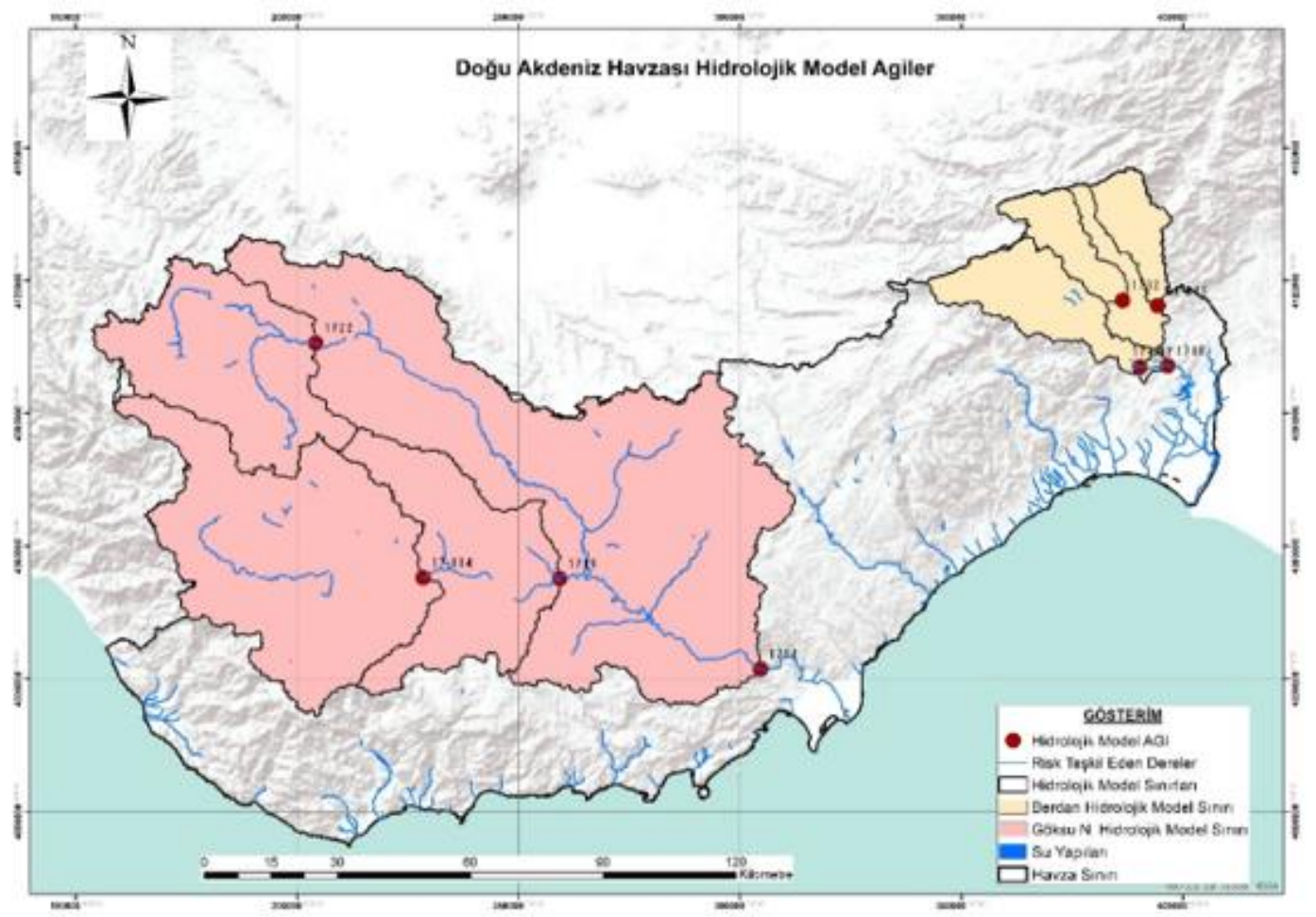

Şekil 3. Doğu Akdeniz Havzası hidrolojik modelinde kullanılan AGİ dağılım haritası

\subsection{Hidrolojik Model}

Hidrolojik modelleme çalışması için Danimarka Hidrolik Enstitüsü (DHI) tarafından geliştirilen ve uluslararası kabul görmüş olan MIKE 11 modelinin içinde bulunan NAM (yağış-akış modeli) kullanılmıştır. Doğu Akdeniz Havzası için, 2 alt havzada 2 farklı model kurulmuştur. Havzanın doğusunda bulunan 1 numaralı alt havzada (Berdan) 01/02/1963 ile 31/12/1998 ve 2 numaralı alt havzada (Göksu) ve 01/06/1996 ile 01/12/2003 tarihleri arasını kapsayacak şekilde 3 hidrolojik - hidrodinamik model çalışması yapılmıştır.

DHI tarafından gerçekleştirilen dünyanın en yaygın ve kapsamlı hidrodinamik modelleme programı olan MIKE 11 içerisindeki yağış-akış modülünün NAM yöntemi kullanılarak hidrolojik model kurulmuş ve otomatik kalibrasyon aracı kullanılarak istenilen hidrolojik modelin kurulumu hassas bir şekilde sağlanabilmiştir. MIKE 11 NAM modeli temel olarak yağış, buharlaşma, sıcaklık ve debi ölçümlerine ihtiyaç duyan hidrometeorolojik veri tabanlı bir modeldir (Şekil 4). Bu veriler kullanılarak modelin kalibrasyonu ve aynı zamanda doğrulaması ile havza parametrelerinin tanımlanması ve başlangıç koşullarının belirlenmesi mümkün olmaktadır. Temel meteorolojik veriler, yağış serileri, potansiyel buharlaşma serileri ve kar toplanması ve erimesinin de modellenmesi durumunda sıcaklık serileri olarak sayılabilir. Bu şekilde, model akış serileri, ara havza kanal akışları ve aynı zamanda toprak nemliliği, yeraltı suyu beslemesi gibi hidrolojik döngünün toprak fazıyla ve diğer unsurlarıyla ilgili bilgiler üretir.

Genellikle devamında açıklanan hedefler model kalibrasyonu boyunca hesaba katılır: Yağış akış modelinin oluşturulmasında, DHI tarafından geliştirilmiş olan MIKE 11 yazılımında bulunan Yağış-Akış modülünün içerisindeki NAM yöntemi kullanılmıştır. Yöntemin kullanılması için gerekli veriler; yağış, sıcaklık, buharlaşma, ölçülmüş debi ve yağış alanlarının yükseklik dağılımı şeklinde özetlenebilir. MGM 'den alınmış olan yağış, sıcaklık ve buharlaşma verileri; modelde girdi olarak kullanılırken, DSİ'den elde edilen ölçülmüş debi değerleri ulaşılması arzulanan kalibrasyon verileri olarak değerlendirilmiştir. Aynı zamanda kar yağışı ve erimesini de modele dâhil edebilmek amacıyla, yağış alanlarının kot dağılımı ile, MGİ 'lerin 
kurulu olduğu kotlar modele girilir. Oluşturulan hidrolojik modellerden üretilen debi değerlerini değerlendirmek ve akışı yönlendirebilmek için bir MIKE 11 hidrodinamik nehir modeli oluşturulur.

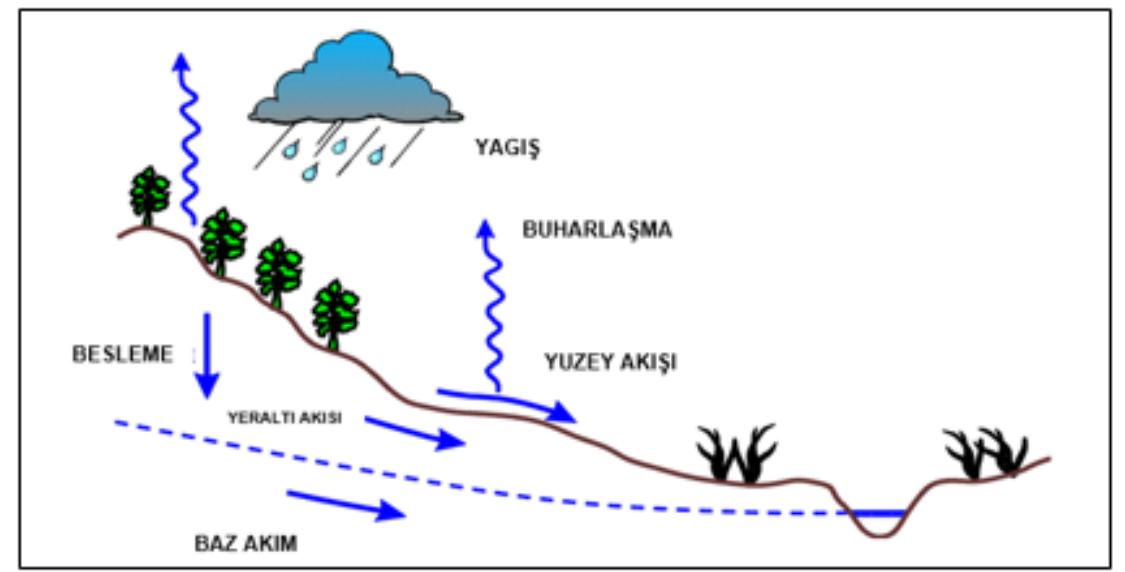

Şekil 4. NAM yönteminin çalışma metodolojisi

\section{4. İstatistiksel Yöntemler}

Taşkın hidrograflarının 10, 50, 100, 500 ve 1000 yıllık taşkın debileri için nasıl belirlendiği aşağıda anlatılmıştır. Yağış-akış modülünün girdi olarak sağlandığı ve aynı zamanda barajlarla birlikte oluşturulan hidrodinamik modelin sonuçları Uç Değer Analizi EVA (Extreme Value Analysis) ile değerlendirilir. Bu değerlendirmeyi yapmak için MIKE Zero yazılımı içerisindeki EVA modülü kullanılmıştır (Şekil 5). EVA modülü kullanarak, modelin içerisindeki her noktadan uç değer analizi yapmak ve dolayısıyla taşkın hidrografları belirlemek mümkündür. Sadece günlük verilerin mevcut olması sebebiyle, gerçekçi sonuçlar elde edebilmek için yalnızca $1000 \mathrm{~km}^{2}$ 'den daha büyük yağış alanına sahip noktalarda model çıktıları kullanılmıştır.

MIKE'ın EVA modülü içerisinde birçok istatistiksel analiz yapmak mümkündür. Aşağıdaki modül görüntülerinde mevcut olan dağılım seçenekleri ve test yöntemleri görülebilir. Yapılan karşılaştırmalar ve testler sonucunda Doğu Akdeniz Havzası, Berdan Nehri Modeli için Weibull Dağılım yönteminin "LMomentler yöntemi" ve Göksu Nehri için genel olarak Weibull yönteminin "Momentler yöntemi" yaklaşımının en uygun yöntem olduğu anlaşılmıştır.

Tablo 1. (MIKE-EVA) ile yapılan istatiksel analiz sonuçları

\begin{tabular}{|c|c|c|c|c|c|c|c|c|c|c|c|c|}
\hline & & & & & & & D/E Combinatio & & & & & \\
\hline & Return Period [years] & GEV/MOM & JGEV/ML & GEV/LMOM & GUM/MOM]G & GUM/ML & GUM/LMOM & LN2/MOM & \begin{tabular}{|l|} 
LN2/ML \\
\end{tabular} & LN2/LMOM V & WEIMOM & WEILMOM \\
\hline \multirow{8}{*}{ Estimated quantile } & 2.00 & 172.497 & 177.392 & 166.162 & 184.219 & 185.707 & 190.991 & 185.022 & 185.022 & 185.022 & 156.693 & 158.887 \\
\hline & 5.00 & 271.342 & 246.698 & 234.433 & 308.414 & 253.697 & 278.756 & 263.251 & 263.234 & 254.237 & 240.102 & 248.454 \\
\hline & 10.00 & 353.196 & 301.594 & \begin{tabular}{|l|l|}
305.313 \\
\end{tabular} & 390.642 & 298.713 & 336.864 & 316.536 & 316.505 & 300.181 & 333.990 & 340.727 \\
\hline & 25.00 & 480.033 & 383.245 & 440.971 & $\begin{array}{l}494.537 \\
\end{array}$ & 355.590 & 410.284 & 385.293 & 385.241 & 358.357 & 494.281 & 489.335 \\
\hline & 50.00 & 594.582 & 454.152 & 590.599 & 571.612 & 397.785 & 464.750 & 437.460 & \begin{tabular}{|l|l|}
437.392 \\
\end{tabular} & 401.805 & 640.963 & 619.581 \\
\hline & 100.00 & 729.049 & 534.641 & 799.242 & 648.119 & 439.668 & 518.815 & 490.392 & 490.304 & 445.368 & 808.326 & 763.788 \\
\hline & 500.00 & 1140.888 & 767.469 & 1661.476 & 824.913 & 536.454 & 643.750 & 617.953 & 617.817 & 548.543 & 1272.198 & 1147.552 \\
\hline & 1000.00 & 1373.069 & 891.902 & 2296.867 & 900.920 & 578.064 & 697.462 & 675.376 & \begin{tabular}{|l|}
675.216 \\
\end{tabular} & 594.276 & 1502.868 & 1332.283 \\
\hline \multirow{8}{*}{ Average quantile } & 2.00 & 173.598 & 177.394 & 166.227 & 184.224 & 185.709 & 190.991 & 185.027 & \begin{tabular}{|l|}
185.027 \\
\end{tabular} & 185.026 & 156.970 & 158.900 \\
\hline & 5.00 & 277.112 & 246.682 & 234.371 & 308.399 & 253.686 & 278.762 & 263.260 & 263.226 & 254.251 & 242.993 & 248.436 \\
\hline & 10.00 & 360.103 & 301.578 & 304.981 & 390.613 & 298.692 & 336.874 & 316.550 & \begin{tabular}{|l|}
316.488 \\
\end{tabular} & 300.204 & 337.088 & 340.691 \\
\hline & 25.00 & 485.057 & 383.264 & 440.033 & 494.491 & 355.558 & 410.298 & 385.317 & 385.214 & 358.396 & 495.370 & 489.321 \\
\hline & 50.00 & 594.940 & 454.240 & 589.051 & 571.554 & 397.744 & 464.768 & 437.494 & 437.357 & 401.858 & 638.929 & 619.635 \\
\hline & 100.00 & 721.113 & 534.858 & $\begin{array}{l}797.095 \\
\end{array}$ & 648.047 & 439.618 & 518.837 & 490.438 & 490.263 & 445.437 & 801.904 & 763.965 \\
\hline & 500.00 & \begin{tabular}{|l|}
1093.897 \\
\end{tabular} & 768.354 & 1660.679 & 824.812 & 536.384 & 643.780 & 618.036 & 617.764 & 548.656 & 1251.279 & 1148.254 \\
\hline & 1000.00 & 1297.450 & 893.329 & 2300.830 & 900.806 & 577.985 & 697.495 & 675.479 & 675.160 & 594.411 & 1474.082 & 1333.324 \\
\hline \multirow{8}{*}{ Standard deviation } & 2.00 & 3.162 & 1.310 & 1.336 & 2.458 & 1.342 & 1.734 & 1.476 & 1.476 & 1.330 & 1.655 & 1.366 \\
\hline & 5.00 & 5.201 & 2.347 & 2.745 & 4.096 & 2.063 & 2.785 & 2.440 & 2.439 & 2.130 & 9.033 & 3.729 \\
\hline & 10.00 & 8.493 & 3.769 & 6.120 & 5.532 & 2.649 & 3.656 & 3.405 & 3.403 & 2.924 & 12.623 & 6.748 \\
\hline & 25.00 & $\begin{array}{l}17.507 \\
\end{array}$ & 6.972 & 17.930 & 7.465 & 3.435 & 4.822 & 4.892 & 4.889 & 4.126 & 16.902 & 13.396 \\
\hline & 50.00 & 29.100 & 10.676 & 36.478 & 8.938 & 4.035 & 5.711 & 6.158 & 6.155 & 5.132 & 26.123 & 20.518 \\
\hline & 100.00 & \begin{tabular}{l|l}
45.995 \\
\end{tabular} & 15.767 & 69.384 & \begin{tabular}{|c|}
10.417 \\
\end{tabular} & 4.638 & $\begin{array}{ll}6.603 \\
\end{array}$ & 7.541 & 7.536 & 6.216 & 43.763 & 29.406 \\
\hline & 500.00 & 114.066 & 34.787 & 264.943 & 13.871 & 6.049 & 8.689 & 11.204 & 11.196 & 9.031 & 117.154 & 56.633 \\
\hline & 1000.00 & 160.700 & 47.108 & 454.471 & 15.365 & 6.661 & 9.591 & 12.981 & 12.971 & 10.373 & 162.832 & 71.118 \\
\hline \multirow{2}{*}{ oodness-of-fit statistics } & 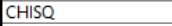 & 1746.321 & 990.080 & 361.460 & 3622.504 & 455.124 & 2415.241 & 1818.204 & 818.204 & 1438.314 & 156.241 & 144.723 \\
\hline & & 10 & 0.137 & 0.083 & 275 & 0.172 & 167 & 152 & 0.152 & 0.166 & 0,128 & 0,0 \\
\hline
\end{tabular}


Uç değer analizleriyle birlikte 10, 50, 100, 500 ve 1000 yıllık taşkın tekerrür debileri için pik debi değerleri belirlenmiştir. Bu değerler, ayrıca sentetik yöntemler kullanılarak belirlenen baz akımlarla birleştirilerek, taşkın tekerrür debileri elde edilmiş ve Tablo 1'de sunulmuştur.

Doğu Akdeniz havzasında hidrolojik model için yağış toplanma sürelerine göre 2 farklı alt havza tespit edilmiştir. Bu alt havzalardan 1 Numaralı model olan Berdan Alt Havzası ve 2 No'lu model olan Göksu Alt Havzasında 4'er adet uzun dönem verisi bulunan AGI'ler kullanılmıştır. Kalibrasyon periyodunun sahadaki güncel durumu yansıtması adına bu AGI'lere ait bütün veriler kalibrasyon için kullanılmıştır. Daha sonra kalibre edilen hidrolojik model hidrodinamik olarak modellenip, dere hatları akışa geçirilmiştir. $\mathrm{Bu}$ sayede kesitlerle tanımlı olan dere ağları üzerinde istenilen herhangi bir kesit noktasından tekerrür debileri ve dolayısı ile hidrograf çıkarabilmek mümkündür.

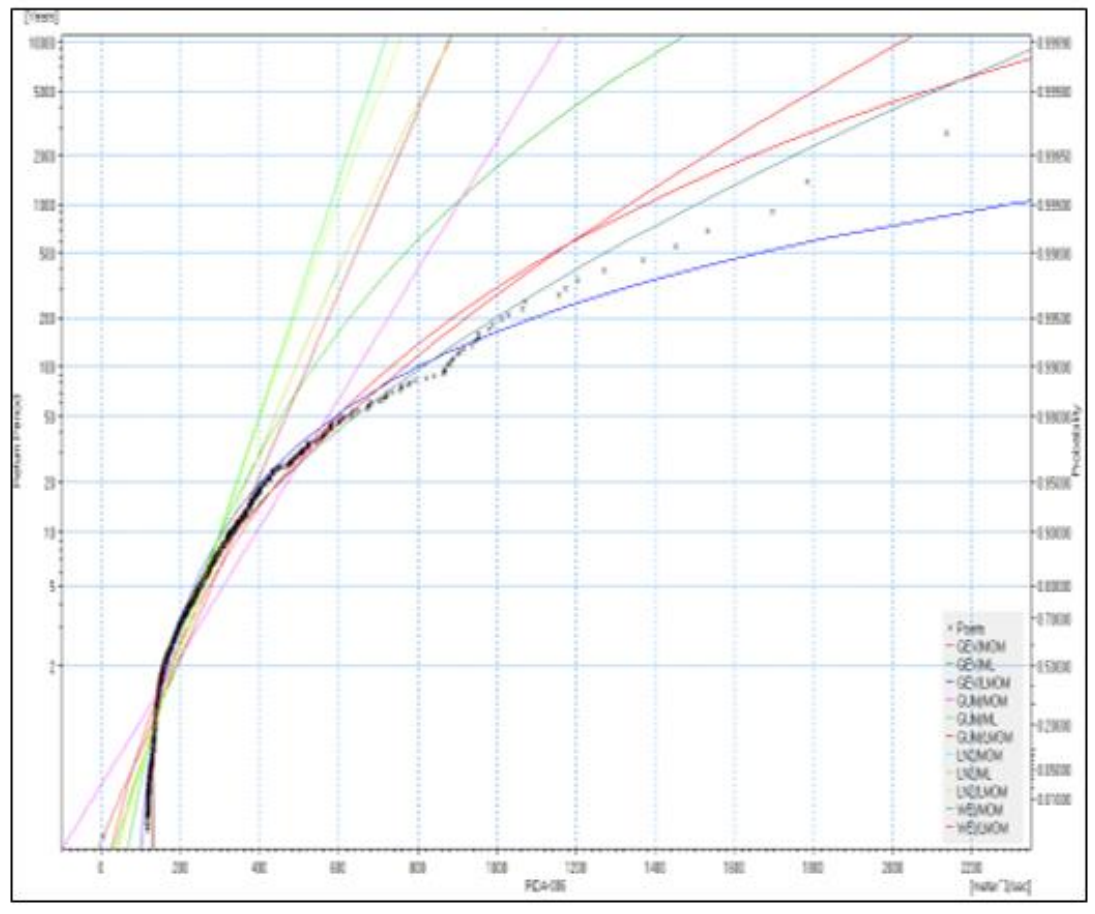

Şekil 5. Model çıktılarından üretilen tekerrür yıl1-debi olasılık grafiği

\section{BULGULAR VE TARTIŞMA}

Çalışmalar sonucunda önceden belirlenmiş hidrolik modelleme yapılacak riskli dere kollarının her biri için; $10,50,100,500$ ve 1000 yıllık taşkın tekerrür debileri saptanarak hidrograflar hazırlanmıştır. Belirlenen hidrograflar, ilerleyen aşamalarda kurulacak hidrolik modellerde memba şartı olarak kullanılacak ve bu debiler kullanılarak hidrodinamik taşkın modelleri oluşturulacaktır. Bu nedenle proje kapsamında yapılan çalışmalarda belirlenen risk noktaları için hidrodinamik model çalışmaları göz önünde bulundurulmuş, ağırlıklı olarak ara alt alanlar belirlenerek taşkın hesaplamaları gerçekleştirilmiştir. Hidroloji çalışmaları yapılırken, yeterli düzeyde güvenilir bilgi edinilmesi mümkün olan alanlarda kurulmuş olan hidrolojik model çıktıları kullanılarak yineleme debileri elde edilmiştir.

Havza içinde riskli olarak saptanan her nokta için uluslararası kabul görmüş sentetik yöntemler, NTFA ve BTFA (Noktasal ve Bölgesel Taşkın Frekans Analizi) kullanılarak hidroloji hesaplamaları yapılmıştır. Noktasal ve Bölgesel Taşkın Frekans analizi çalışmalarında hesap yapılabilen noktalar için ilgili kesitin tüm yağış alanı dikkate alınarak yapılmıştır. Hidrolojik model kurulumu aşamasında sırasıyla gerekli olan noktalarda NAM yöntemi kullanılarak yağış akış modeli kurulmuş ve kalibre edilmiş, suyun rotasını ve havza içerisindeki hareketini modelleyebilmek amacıyla hidrodinamik model kurulmuş ve çıkan 
sonuçlardan ekstrem değer analizi yapılmış ve son olarak istatistiksel yöntemler kullanılarak gerekli taşkın tekerrür debileri için hidrograflar oluşturulmuştur. Hidrolojik model için DHI tarafindan geliştirilen ve uluslararası kabul görmüş olan MIKE 11 modelinin içinde bulunan NAM yağış akış modeli kullanılmıştır.

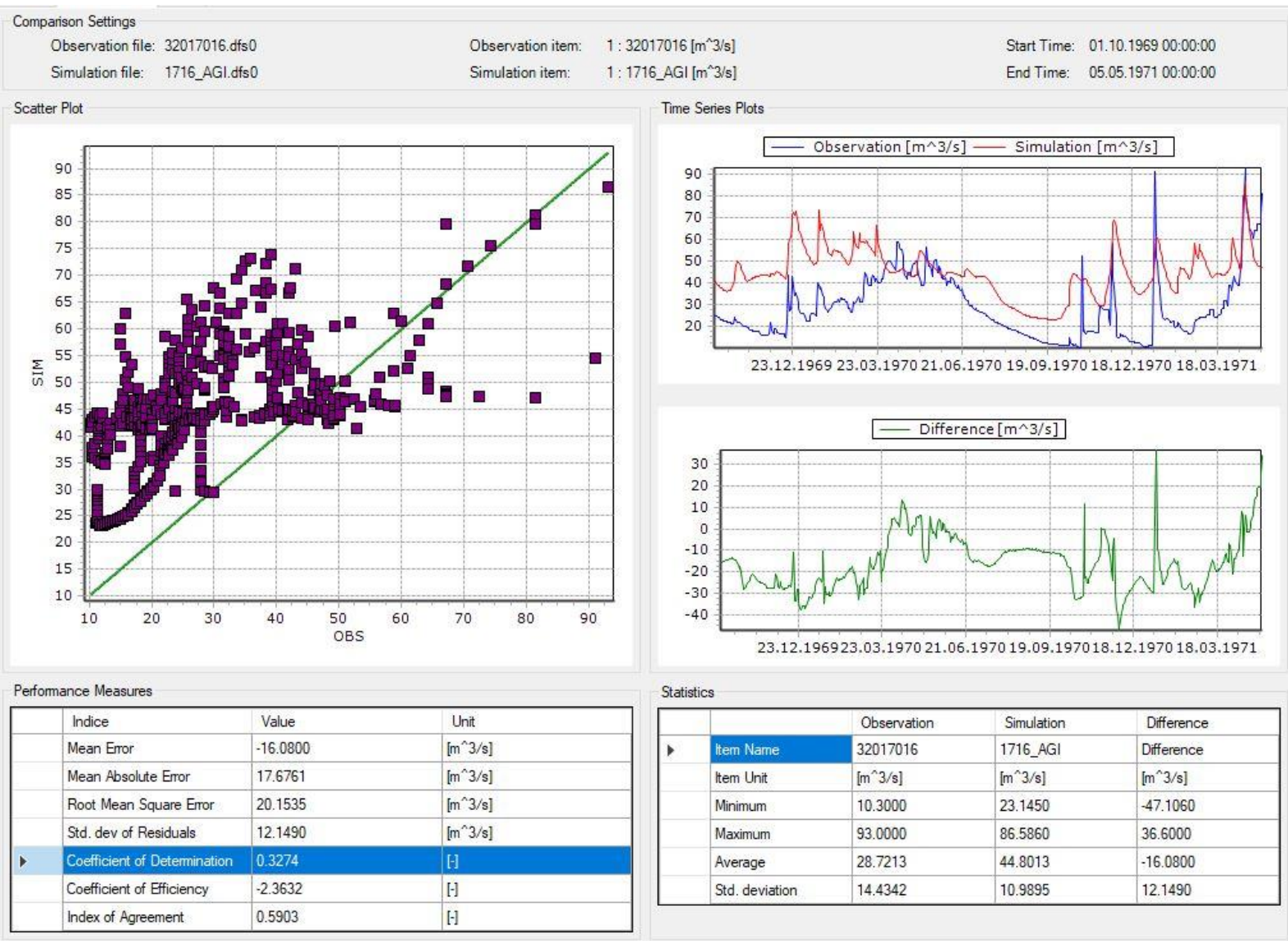

Şekil 6. 1 Numaralı alt havzada Berdan Nehri model sonuçları ile 1716 no'lu akım gözlem istasyonu akım değerlerinin karşılaştırılması

Doğu Akdeniz havzasında hidrolojik model için uygun veri varlığı ve yağış toplanma sürelerine göre 2 farklı alt havza tespit edilmiştir. Bu alt havzalardan 1 numaralı model olan Berdan Alt Havzası ve 2 numaralı model olan Göksu Alt Havzasında 4'er adet uzun dönem verisi bulunan AGI'ler kullanılmıştır. Kalibrasyon periyodunun sahadaki güncel durumu yansıtması adına bu AGİlere ait bütün veriler kalibrasyon için kullanılmıştır. Daha sonra kalibre edilen hidrolojik model hidrodinamik olarak modellenip, dere hatları akışa geçirilmiştir. Bu sayede kesitlerle tanımlı olan dere ağları üzerinde istenilen herhangi bir kesit noktasından tekerrür debileri ve dolayısı ile hidrograf çıkarabilmek mümkün olmuştur. Bu nedenle validasyon aşaması için dere ağı üzerinde görece kısa dönem verisi olan akım gözlem istasyonları kullanılarak hidrodinamik model sonucu ile bu sözü edilen AGİ verileri karşılaştırılmış ve sonuç doğrulamasına bu yöntemle gidilmiştir. 1 numaralı havzada model simülasyon sonuçları ölçülen değerlerden yüksek çıkmıştır. Buna karşın 2 numaralı havzaların karşılaştırma sonuçlarının bu derece uyumlu olması bu denli büyük nehir hatlarında kurulan modelin sonuçlarının güvenirliliğini ortaya koymaktadır. Her iki model de kararlılık katsayısı 0,3'un üzerinde çıkmıştır. Model sonuçları ile ilgili akım gözlem istasyonlarının akım değerlerinin karşılaştırılması Şekil 6 ve Şekil 7’de verilmiştir. 


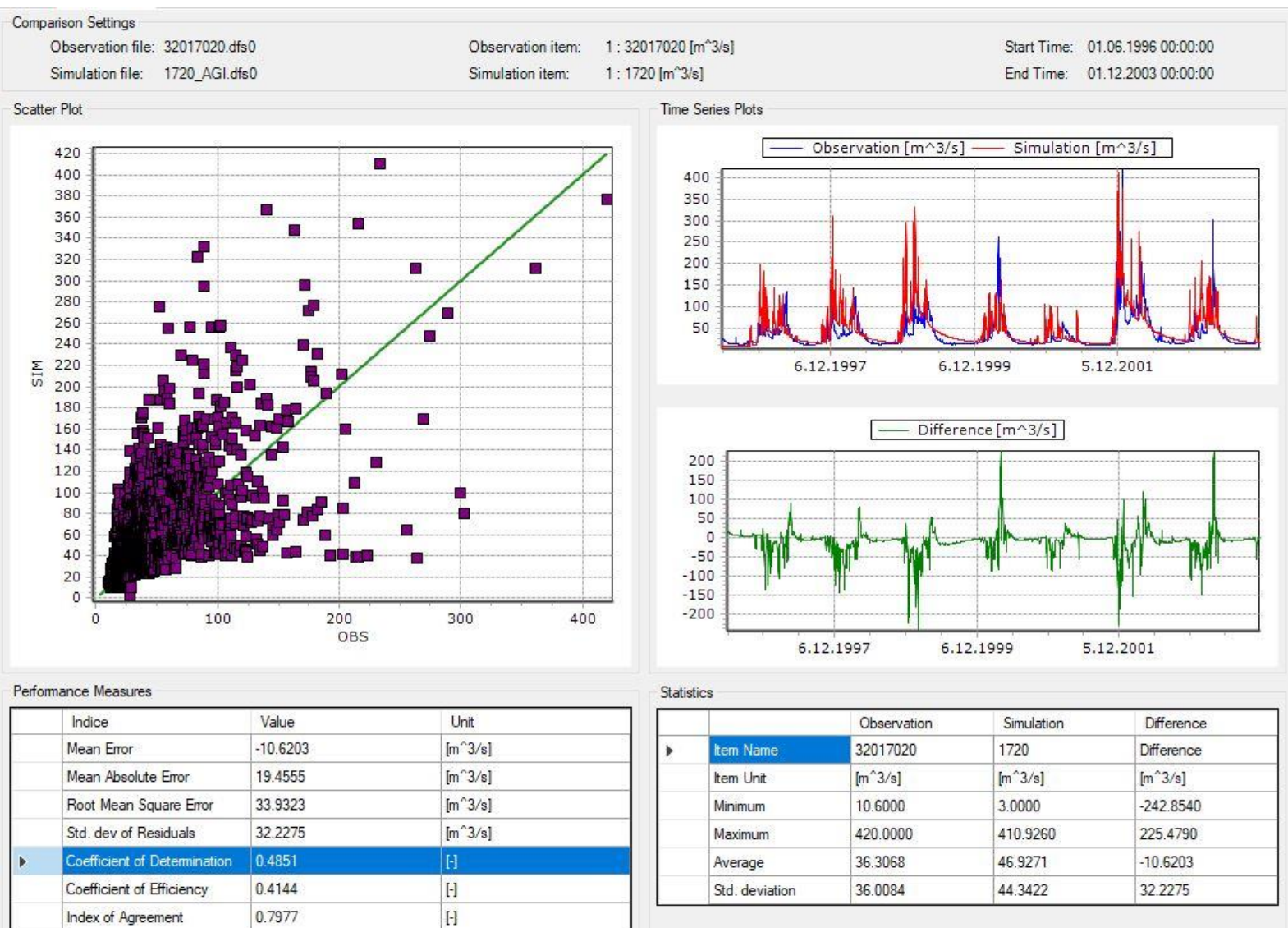

Şekil 7. 2 Numaralı alt havzada Göksu Nehri model sonuçları ile 1720 no’lu akım gözlem istasyonu akım değerlerinin karşılaştırılması

Doğu Akdeniz Havzası için, 2 alt havzada farklı model kurulmuştur. Havzanın kuzeyinde bulunan 1 numaral1 alt havzada 01/02/1963 ile 31/12/1988 ve 2 numaral1 alt havzada 01/06/1996 ile 01/12/1993 tarihleri arasını kapsayan 2 hidrolojik-hidrodinamik model kurulmuştur. Doğu Akdeniz Havzası içerisinde bulunan 73 adet AGI'nin 5 adedi kullanılarak hazırlanan hidrolojik modelde, her bir AGİ'nin yağış alanları belirlenmiş ve bu yağış alanlarının özellikleri kullanılarak model kurulmuştur. $1000 \mathrm{~km}^{2}$ 'den büyük yağış alanına sahip alanlarda 10, 50, 100, 500 ve 1000 yıllık pik akımları, hidrolojik modelden elde edilen çıtılar üzerinden elde edilmiştir. Yapılan karşılaştırmalar ve testler sonucunda Doğu Akdeniz Havzası 1 numaralı havza için Weibull-Method of Moments 2 numaralı havza için genel olarak Weibull-Method of Moments yaklaşımının en uygun yöntem olduğu anlaşılmıştır. Program ara yüzünde bu karşılaştırmalar ekranda yapılabilmektedir. Yağış alanı 1000 km² $^{2}$ den küçük olan noktalarda klasik yöntemler kullanılarak taşkın hidrografları belirlenmiştir. 


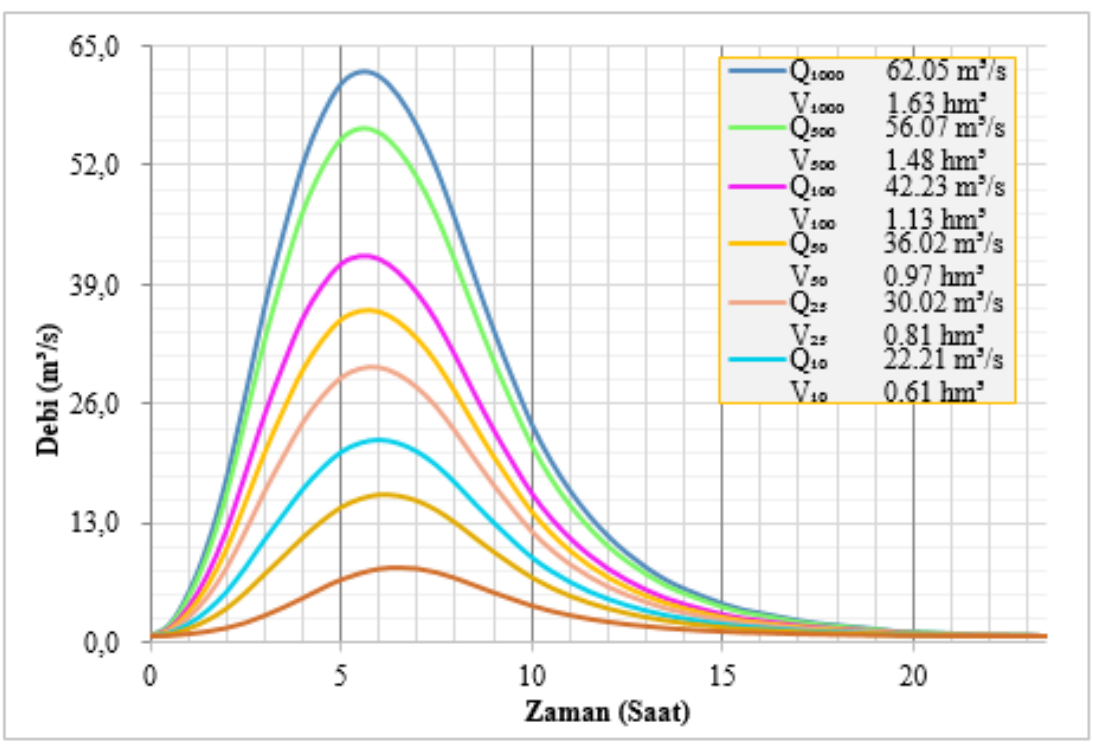

Şekil 8. Sentetik hesaplamalar ile üretilen hidrograflar

Daha küçük yağış alanına sahip olan noktalarda havzadaki yağışın 24 saatten daha kısa sürede akım istasyonuna ulaşması beklenir. Akım gözlem istasyonlarından elde edilen verilerin günlük olması sebebiyle tüm yağışların oluşturduğu akışların istasyonlar tarafından ölçülmesi mümkün olmaz. Bu sebeple küçük havzaların hidrograf hesabı için klasik yöntemler kullanılmıştır. Bunun yanı sıra en az 10 yıl verisi olan akım gözlem istasyonlarıyla Bölgesel Taşkın Frekans Analizi ve noktalarla aynı kolda olan en az 25 yıl verisi olan akım gözlem istasyonları ile Noktasal Taşkın Frekans Analizi gerçekleştirilmiştir. Havzada önceki çalışmalardan elde edilen işletme tesisleri yineleme taşkın debileri saptanmıştır. Bu çalışmalar ise model ve sentetik yöntemler ile hesaplanan sonuçlar ile karşılaştırılmıştır. Seçilen noktaların yinelemeli $(10,50,100,500$ ve 1000) taşkın pik debi ve hidrografları, etkili yağış değerlerinin birim hidrografi koordinatlarıyla çarpılmasıyla ve akış hidrograflarına dönüştürülmesiyle elde edilmiş ve Şekil 8'de sunulmuştur.

\section{SONUÇ}

28 MGİ ve 32 AGİ 'nun verilerinin kullanıldığ 21682,8 km² alana sahip Doğu Akdeniz havzası için birçok taşkın debisi hesaplama yönteminin kıyaslaması yapılmıştır. Geniş bir alanda birçok senaryoya göre havzaların taşkın debileri hesaplanmış model kalibrasyonu ile Manning katsayısı bölgeden bölgeye bulunmuştur. Taşkın debisinin en uygun olanı, maksimum debiyi veren şeklinde tasnif edilmiştir. Alanların büyüklügüne göre tasnif edilen taşkın debilerinden elde edilen sonuçlar şöyle genel bir eğilim göstermiştir. Yağış alanı $1 \mathrm{~km}^{2}$ 'den küçük noktalar için Rasyonel Yöntem, 1-10 km² arasında olan noktalar için Mockus, 10 - $1000 \mathrm{~km}^{2}$ arasında olan noktalar için DSİ Sentetik yönteminin sonuçlarının kullanılması uygun bulunmuştur. $1000 \mathrm{~km}^{2}$, den büyük noktalar için 1 noktada Snyder Birim Hidrograf Yönteminin sonuçlarının kullanılması uygun bulunmuştur. Hidrolojik Model çıktıları diğer hesap yöntemlerine göre küçük kalmıştır. Yağış alanının büyüklüğüne göre de en uygun yöntemler arasında yer almamıştır.

Hidrolojik model yöntemlerinin daha deterministik olması, verilerin doğrulanması, bilgisayar programlarının en hassas değere göre çalışması, taşkın debilerinin daha küçük kalmasına sebep olmuştur. Özellikle su yapılarının boyutlandırılmasında hem emniyet hem de ekonomik açıdan uygun olanın bulunması için yöntemler tartışma konusudur. Sentetik yöntemler veya istatistik yöntemler ile bulunan taşkın debilerinin daha emniyetli bir değerde olması ise doğaldır. Sentetik yöntemler için, özellikle avam projeler aşamasında pratikte kullanılmasının yanında, nihai deterministik hesap yöntemleri ile de kalibrasyon yapılmaktadır. 
Havza alanının büyüklüğü taşkın debisi için yöntem belirlemede en önemli faktördür. İlaveten, havza alanı büyüdükçe istatistik yöntemler daha uygun sonuçlar vermiştir. Büyük alanlar için çoğu zaman deterministik (hidrolojik) yöntemlerin uygulanma güçlüğü ortadadır. Ancak; sonuç olarak sentetik, istatistik ve deterministik yöntemlerin her üçünü birlikte kullanıp, en yüksek taşkın debisini veren değerin kabul edilmesi, hidrolik modellemeyi ve taşkın risk haritalarını buna göre belirlemesi gerekmektedir.

\section{TEŞEKKÜR BÖLÜMÜ}

$\mathrm{Bu}$ çalışmada kullanılan verilerin temini için Orman ve Su İşleri Bakanlı̆̆ $\mathrm{Su}$ Yönetimi Genel Müdürlügü̈'ne teşekkür ederiz.

\section{KAYNAKLAR}

[1] Gray D.M, (1970). Principles of Hydrology, National Research Council of Canada.

[2] U.S. Soil Conservation Service, (1975). "Urban Hydrology for Small Watersheds," Technical Release No.55, Washington, DC.

[3] Taylor A.B, Schwartz, H.E,. (1942). "Unit Hydrograph Lag and Peak Flow Related to Basin Characteristics", Transactions, American Geophysical Union 33.

[4] Mitchell W.D, (1948). "Unit Hydrographs in Illionis Division of Water Ways", State of Illionis, Springfield, Illionis.

[5] Williams H.M, (1945). "Discussion on Military Airfields: Design of Drainage Facilities." Transactions American Society Civil Engineering, 110.

[6] Commons G.G, (1962). Flood Hydrographs, Civil Engineering, 12.

[7] Snyder F.F, (1938). Synthetic Unit Graphs, Transactions American Geophysical Union, 19.

[8] Önöz B., Bayazıt M, (2007). "Flood and drought hydrology,” İstanbul, 46-48.

[9] Sönmez O, ve ark., (2012). "İstanbul Derelerinin Taşkın Debilerinin Tahmini”, SAÜ. Fen Bilimleri Dergisi,16. Cilt, 2. Say1, s. 130-135, Sakarya.

[10] Çavdar S.K, (1996). "İstanbul Dereleri İçin Taşkın Debilerinin Araştırılması”, İTÜ Fen Bilimleri Enstitüsü, Yüksek Lisans Tezi, İstanbul.

[11] Hepdoğar R, (1988). “B. Çekmece Gölü Havzasının Hidrolik ve Hidrolojik Karakteristikleri”, İTÜ Fen Bilimleri Enstitüsü, Yüksek LisanTezi, İstanbul.

[12] Arslan B, (1997). "S.C.S. Sentetik Birim Hidrograf Yönteminin Türkiye Şartlarında Uygulanabilirliğinin Araştırılması”, İTÜ Fen Bilimleri Enstitüsü, Yüksek Lisans Tezi, İstanbul Teknik Üniversitesi.

[13] Çıtakoğlu H. ve Güney M., (2017). "L-Momentler Yöntemiyle Karadeniz’e Dökülen Akarsulara Ait Yillik Anlik Maksimum Akim Değerlerinin Bölgesel Frekans Analizi”, Ömer Halisdemir Üniversitesi Mühendislik Bilimleri Dergisi, Cilt 6, Say1 2, 571-580.

[14] Çıtakoğlu H., Demir V. ve Haktanır T., (2017). "L-Momentler Yöntemiyle Türkiye’ye Ait Açik Yüzey Buharlaşma Değerlerinin Bölgeselleştirilmesi”, Ömer Halisdemir Üniversitesi Mühendislik Bilimleri Dergisi, Cilt 6, Sayı 2, (2017), 546-559.

[15] Xiong L, Du T, Xu C.Y, Guo S, Jiang C, Gippel J.C, (2014). "Non-Stationary Annual Maximum Flood Frequency Analysis Using the Norming Constants Method to Consider Non-Stationarity in the Annual Daily Flow Series", Water resources management, 29 (10), 3615-3633.

[16] Haktanır T, (2009). "Statistical modelling of annual maximum flows in Turkish rivers". Hydrological Sciences Journal, 36 (4), 367-389.

[17] He J., Anderson, A., Valeo C, (2015). "Bias compensation in flood frequency analysis". Hydrological Sciences Journal, 60 (3), 381-401.

[18] Seçkin N, Haktanır T, ve Yurtal R, (2011). "Flood frequency analysis of Turkey using L-moments method". Hydrological Processes, 25 (22), 3499-3505. 
[19] Tosunoğlu ve ark., (2017). "Fırat Havzası'ndaki Eksik Akım Verilerinin Debi Süreklilik Çizgileri ve Regresyon Modelleri ile Tahmin Edilmesi”, Iğdır Üniversitesi Fen Bilimleri Enstitüsü Dergisi, Cilt 7, Sayı 4, Sayfalar 85 - 94.

[20] Önöz B., Bayazıt M, (1995). "Best-fit distributions of largest available flood samples". Journal of Hydrology, 167 (1-4), 195-208.

[21] Li Z, Zhao W., Wang Y, (2015). "Probability modeling of precipitation extremes over two river basins in Northwest of China", Advances in Meteorology, 374127.

[22] Phien H.N, Laungwattanapong N, (1991). "At-site flood frequency analysis for Thailand", Water SA, 17 (2), $147-154$.

[23] Patra J.P, Kumar R, Mani P, (2016). "Combined fluvial and pluvial flood inundation modelling for a project Site", Procedia Technology, 24, 93-100.

[24] Andrei A, Robert B, Erika B, (2017). "Numerical Limitations of 1D Hydraulic Models Using MIKE11or HECRAS software-Case study of Baraolt River," Romania IOP Conference Series: Materials Science and Engineering 245, 072010.

[25] Bhattacharya B, Islam T, Masud S, Suman A ve Solomatine D.P, (2016). "The use of a flood index to characterise flooding in the north-eastern region of Bangladesh", FLOOD risk 2016-3rd European Conference on Flood Risk Management, E3S Web of Conferences, 7, 10003.

Geliş/Received: 26 Haz 2019/26 Jun 2019

Kabul Ediliş/Accepted: 02 Eki 2019/02 Oct 2019 